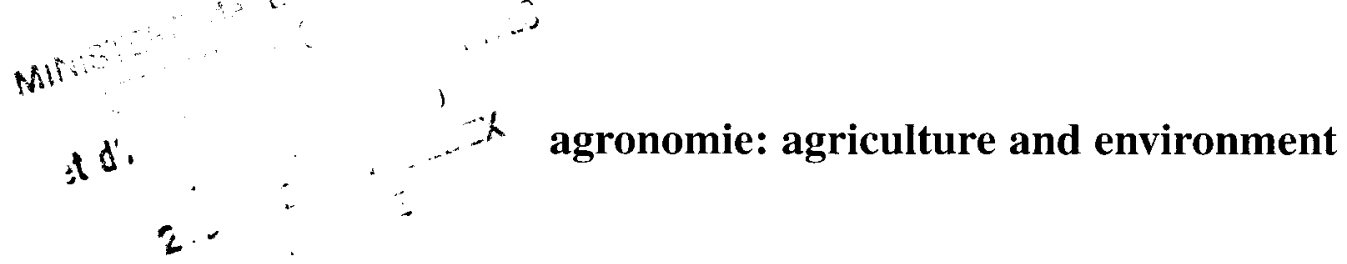

\title{
Conditions d'apparition du ruissellement dans les cultures annuelles de la région lémanique. Relation avec le fonctionnement des exploitations agricoles
}

\author{
JY Vansteelant ${ }^{1}$, D Trévisan ${ }^{*}$, L Perron ${ }^{3}, \mathrm{JM}_{\text {Dorioz }}{ }^{2}, \mathrm{D}$ Roybin ${ }^{3}$ \\ 'GIS Alpes-du-Nord - Inra: \\ 2 Inra, 75, avenue de Corzent, BP 511, F-74203 Thonon-les-Bains ; \\ ${ }^{3}$ GIS Alpes-du-Nord - Inra, 11, rue Métropole, F-73000 Chambéry, France
}

(Reçu le 5 janvier 1996 ; accepté le 16 décembre 1996)

\begin{abstract}
Summary - Frequency of runoff in the cropped area of the French basin of Lac Léman. Agricultural runoff from the Chablais region of France, is believed to contribute to the pollution of the waters of Lac Leman (Lake Geneva). This study aimed at determining which factors influence the frequency of runoff from agricultural lands Two hundred agricultural fields under a wide diversity of agricultural practices were monitored during a winter and a summer period. For each field the kinetics of formation of superficial soil crusting that can prevent infiltration of rainfall into deeper soil layers was evaluated and the presence of runoff was observed. Additionally, the farmers were surveyed to determine the specific agricultural practices that were used on each field. The observations showed that both Hortonian and non-Hortonian runoff occurred. Sheet runoff was observed as well as runoff following tracks of cultivation equipment. The frequency of runoff varied among agricultural practices. Fields cultivated with nonrotative implements had a higher frequency of runoff than fields cultivated with rotative implements. Fields in long periods of rotation of corn or other crops without mulching showed high frequencies of runoff. A scale of runoff risk was developed to compare the frequency with which the different farming systems in Chablais produced runoff. For each farming pratice this scale takes into account, at the field level, the kinetics of the development of impermeable soil crusting and the duration of the time the field is at risk to produce runoff. Fields on which the mechanization and rotational practices of traditional systems are used have the highest risk of producing runoff per unit area. Intensive farmiing systems have a lower risk of producing runoff per unit area. Intensive farming systems have a lower risk of producing runoff per unit area. However, because of the relatively small land area presently devoted to the traditional farming systems, both intensive and traditional systems contribute equally to the pollution of Lake Leman. As a result of this work, changes in traditional and intensive practices are suggested that are believed to enhance agricultural sustainability on the French shores of Lake Leman and reduce environmental impacts.
\end{abstract}

runoff / erosion / diffuse pollution / farming system / sustainable agriculture / soil crusting

Résumé - Afin de déterminer les facteurs qui contrôlent le ruissellement des terres agricoles et de mettre en évidence les situations et périodes à risque, nous avons observé ses symptômes pendant une année, sur 200 parcelles de cultures annuelles représentatives des conditions de milieu et de pratiques culturales de la rive française du lac Léman $\left(400 \mathrm{~km}^{2}\right)$. Les résultats obtenus mettent en évidence que le ruissellement affecte la moitié des parcelles et présente une

* Correspondance et tirés à part.

Tél : (33) 0450267800 ; fax : (33) 0450260760 
grande diversité de formes et d'origines. Les formes liées à la dégradation structurale superficielle des sols prédominent. Leur précocité et leur fréquence dépendent surtout des pratiques culturales. Ainsi, les chantiers de récolte laissant le sol nu, certaines pratiques comme l'implantation des cultures réalisées par de nombreux passages d'outils traînés ou les successions de culture dans lesquelles le maïs revient souvent, favorisent la battance ou le tassement des sols et constituent des facteurs de risque de ruissellement. Sur ces bases, nous construisons une échelle de risque de ruissellement en fonction des pratiques et des rotations. Elle permet une analyse comparée des risques potentiels de ruissellement des divers systèmes d'exploitation de la région étudiée. Les fonctionnements d'exploitation traditionnels, présentent les plus fortes proportions de surface cultivée à risque de ruissellement, du fait de leur équipement et de leurs rotations. Cependant, à l'échelle de la région, le risque global lié à ce type d'exploitation reste limité en raison de la faible extension de leurs cultures annuelles. Les exploitations en début d'intensification appliquent les mêmes pratiques à risque, mais sur de vastes surfaces. Elles sont de ce fait, à l'échelle de la région, à l'origine d'un risque de ruissellement important. Les exploitations les plus intensives présentent des proportions de surface à risque beaucoup plus limitées, compte tenu d'un équipement et de rotations qui limitent les problèmes de dégradation structurale des sols. Néanmoins, ce type d'exploitation contribue de façon importante au risque global, en relation avec la forte surface des cultures annuelles qu'il gère. Le travail réalisé permet de proposer des axes d'action différenciés selon les types d'exploitation, pour favoriser des pratiques agricoles limitant le risque de ruissellement et, au-delà, le transfert de polluants vers les eaux de surface.

\section{ruissellement / érosion / pollution diffuse / système d'exploitation / agriculture durable / battance}

\section{INTRODUCTION}

Le ruissellement sur les terres agricoles est à l'origine du transfert vers les eaux de surface de divers polluants (phosphore, métaux lourds, pesticides, pathogènes) susceptibles de dégrader la qualité des rivières et des plans d'eau (eutrophisation, contaminations, colmatage des frayères). Dans les bassins versants des grands lacs, ce type de pollution fait l'objet d'une attention accrue depuis que les rejets d'eaux usées commencent à être maîtrisés (Novotny, 1994). Ainsi, pour assurer le succès des opérations de restauration de la qualité du lac Léman, la Commission internationale pour la protection des eaux du Léman (Cipel) estime indispensable de réduire les transferts de phosphore $(\mathrm{P})$ provenant du ruissellement et de l'érosion associée des cultures annuelles et des vignes (Cipel, 1988).

Dans le contexte des milieux tempérés, le ruissellement peut présenter différentes formes (Monnier et al, 1986 ; Auzet et al, 1990 ; Mosimann et al, 1991). Il est dit diffus lorsque de petites flaques d'eau excédentaires apparaissent dans les dépressions de la surface des sols, se connectent et provoquent des écoulements en nappe. Dans la mesure où l'énergie de ces écoulements est faible, il n'y a pas d'incision de la surface des parcelles par des rigoles ou des ravines, mais plutôt des dépôts de terre en bas de pente. L'incision des sols n'apparaît qu'au-delà d'une vitesse et d'une énergie critique des écoulements. C'est le cas lorsque les pentes sont fortes ou lorsque la longueur des pentes est grande et que les écoulements sont recueillis et concentrés dans des talwegs ou des formes linéaires telles que les traces de roues ou les modelés résultant du passage des engins agricoles.

La battance des sols, qui provoque une forte diminution de la capacité d'infiltration superficielle, est à l'origine de la plupart des phénomènes de ruissellement. Les relations entre battance et érosion hydrique sont bien connues dans le cas des grandes cultures de l'Europe de l'Ouest (Monnier et al, 1986 ; Boiffin et al, 1988 ; Papy et Boiffin, 1988 ; Papy et Douyer, 1991 ; Trévisan et Lelong, 1992 ; Lelong et al, 1993). Selon Monnier et al, 1986, les risques de ruissellement liés à un système de culture, à l'échelle d'une rotation ou d'une année culturale, dépendent de la hauteur de pluie qui tombe sur des sols présentant des structures continues dès la surface. La vitesse et l'intensité de la dégradation de l'état de surface du sol sont contrôlées par plusieurs facteurs : les propriétés texturales et structurales du sol, les pratiques de travail du sol, son histoire hydrique et l'agressivité des averses (Valentin, 1981 ; Boiffin, 1984 ; Le Bissonnais, 1988). Les pratiques agricoles, en organisant dans l'espace les successions de cultures et de techniques, ont une influence prépondérante sur les états de surface des sols et sont reconnues par plusieurs auteurs comme un facteur majeur du ruissellement et de l'érosion dans les bassins versants agricoles (Papy et Boiffin, 1988 ; Ludwig, 1992).

La plupart de ces études ont été réalisées dans le cadre des dépôts limoneux du Bassin parisien à grandes cultures dominantes, contexte très différent de celui de la zone cultivée du bassin lémanique français où les sols sont issus de formations morainiques ; les exploitations agricoles sont tournées vers un élevage laitier, d'où des rotations et des pratiques différentes (Beaujean et Cros, 1993); 
l'organisation du parcellaire est marquée par des parcelles de petites tailles ( 1 à 2 ha en moyenne), une intrication cultures-prairies, ainsi qu'une forte densité de fossés liée au mitage du pourtour du lac par l'urbanisation (Cristofini et al, 1994 ; Cros, 1994).

Cette absence de références adaptées et les enjeux locaux liés à la qualité des eaux dans le bassin lémanique expliquent la mise en place d'une étude sur le ruissellement dans les cultures annuelles de la région la plus cultivée du bassin lémanique français, le Bas-Chablais $\left(400 \mathrm{~km}^{2}\right)$. Notre objectif est de déterminer, dans les situations agropédoclimatiques spécifiques du BasChablais, l'influence des pratiques agricoles et des conditions de milieu sur le ruissellement; de construire une échelle de risque relatif de ruissellement ; de comprendre les logiques de fonctionnement d'exploitations qui conduisent à l'adoption de pratiques favorisant le risque de ruissellement. Cette analyse des relations « risques de ruissellement - pratiques agricoles - fonctionnement d'exploitation » est menée en vue de dégager des propositions d'amélioration adaptées à chaque type d'exploitation. L'ensemble du travail réalisé constitue une base de connaissances utilisable pour la mise au point d'une stratégie régionale de lutte contre les pollutions d'origine agricole.

\section{SITE ET MÉTHODES}

L'objectif de ce travail nécessite de rendre compte de la diversité des causes du ruissellement sur l'ensemble du territoire étudié. Mais il est exclu d'avoir recours à des mesures directes du ruissellement, impossibles à mettre en cuvre dans un dispositif représentatif de la diversité des milieux physiques, des pratiques et des fonctionnements d'exploitation. Il faut donc évaluer indirectement l'intensité du phénomène étudié, d'où le choix d'un suivi qualitatif de ses symptômes, en l'occurrence l'observation de l'évolution de la structure de la surface du sol et des traces d'écoulement laissées sur la parcelle par le ruissellement. De telles observations présentent l'avantage de pouvoir être multipliées dans l'espace et dans le temps et ainsi de refléter la variabilité du territoire étudié. Ce type d'approche est issu des travaux de Boiffin, 1984, sur l'évolution de la battance et de Boiffin et al, 1988, sur les relations battance-érosion.

\section{La démarche adoptée consiste à :}

- définir un large échantillon de parcelles de cultures annuelles représentatives de la diversité des conditions de milieu et de pratiques du site d'études ;

- suivre sur chacune d'elles les symptômes du ruissellement ;

- établir, sur la base de ces observations, un classement relatif des risques de ruissellement ;

- analyser la répartition des risques liés aux pratiques, dans les divers fonctionnements d'exploitation.

\section{Le site d'étude et sa diversité}

\section{Diversité des milieux physiques}

Dans la zone d'étude (fig 1), on distingue trois types de sol (Rieffel, 1975 ; Dupont, 1994) : des sols colluviaux, recouvrant près d'un tiers de la surface, situés à l'aval des pentes des Préalpes calcaires, caractérisés par des textures d'horizon de surface « légères » (teneur en argile $\leq 20 \%$ ) ; des sols tronqués, avec des textures «lourdes » (teneur en argile comprise entre 25 et $30 \%$ ), qui représentent un tiers de la surface et occupent les marges des dépôts morainiques ; des sols faiblement lessivés, sur la moraine de fond proprement dite, qui dominent dans la zone et présentent des textures « intermédiaires » (teneur en argile comprise entre 20 et $25 \%$ ).

Pour chacun de ces types, il existe une variabilité plus ou moins forte des caractéristiques texturales des matériaux, résultant des conditions locales de la pédogenèse et de l'évolution des versants. Du sommet des pentes vers les bas de versant, les textures passent généralement des limons sableux aux argiles limoneuses, ces dernières étant fréquemment marquées par des traces d'hydro-

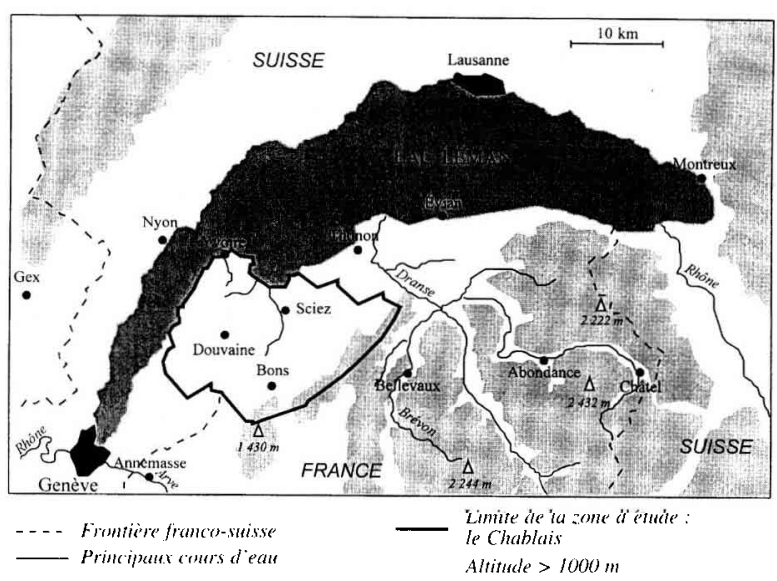

Fig 1. Site d’étude. 
morphie temporaire. Les teneurs en matière organique des horizons de surface sont relativement élevées. Sur 121 échantillons prélevés entre 0 et $20 \mathrm{~cm}$, elles sont comprises entre 2 et $3 \%$. Il s'agit donc de sols a priori peu sensibles à la battance (Marty et Fioramonti, 1970 ; Monnier et Stengel, 1982). Les sols cultivés se situent toujours sur des pentes faibles $(<5 \%)$, entre 450 et $600 \mathrm{~m}$ d'altitude.

\section{Diversité des fonctionnements d'exploitations agricoles et des pratiques associées}

Une typologie des fonctionnements a été établie par Beaujean et Cros (1993) sur la base d'une méthodologie développée dans différents contextes des Alpes du Nord (Cristofini, 1985 ; Roybin, 1991). Un type de fonctionnement corres- pond à une organisation stable dans le temps des systèmes fourragers, d'élevage ou de culture et des activités de commercialisation et de transformation mises en ouvre dans l'exploitation. Dans le Bas-Chablais, le développement agricole s'organise essentiellement autour de cinq types de fonctionnement d'exploitation (tableau I).

Pour les exploitations traditionnelles (TR), l'activité agricole n'est pas la principale source de revenu et est maintenue dans un souci d'entretien du patrimoine. Disposant d'une faible force de travail, la production se concentre sur des ateliers de petite taille (viande et, le plus souvent, cultures de vente), d'où la faible part des cultures annuelles gérées par ces exploitations dans la zone d'étude. L'élevage est en diminution et les cultures annuelles de vente occupent près de $50 \%$ de

Tableau I. Principales caractéristiques des fonctionnements d'exploitation de la zone d'étude.

\begin{tabular}{|c|c|c|c|c|}
\hline $\begin{array}{l}\text { Types de } \\
\text { fonctionnement } \\
\text { d'exploitation } \\
\text { (\% des types } \\
\text { dans la zone } \\
\text { d'étude) }\end{array}$ & $\begin{array}{l}\text { Équipement et } \\
\text { et travail du } \\
\text { sol dominant }\end{array}$ & $\begin{array}{l}\text { Surfaces de cultures } \\
\text { annuelles } \\
\text { moyenne (ha) } \\
\text { (mini; maxi, (ha)) } \\
{[\% \text { de la zone d'étude] }}\end{array}$ & $\begin{array}{l}\text { Principales rotations } \\
\text { (par ordre décroissant } \\
\text { d'importance) }\end{array}$ & $\begin{array}{l}\text { Critères de choix de la } \\
\text { rotation ou type } \\
\text { d'exploitations concernées }\end{array}$ \\
\hline $\begin{array}{l}\text { TR } \\
\text { Exploitations } \\
\text { traditionnelles } \\
(22 \%)\end{array}$ & $\begin{array}{l}\text { - Outils trainés } \\
\text { - Pas de binage }\end{array}$ & $\begin{array}{l}4,1 \\
(0 ; 7,5) \\
{[5 \%]}\end{array}$ & $\begin{array}{l}-\mathrm{Mg}_{[2-5]}-\mathrm{Bl}-\mathrm{O} \text { ou mono- } \\
\text { culture de maïs grain } \\
\text { - (Mf-BI-O) })_{[3-6]}-\mathrm{PT} \mathrm{T}_{[2-6]} \\
\text { - Pas de cultures annuelles }\end{array}$ & $\begin{array}{l}\text { Facilité de conduite et revenus } \\
\text { Production de foin dans les } \\
\text { exploitations laitières }\end{array}$ \\
\hline $\begin{array}{l}\text { DI } \\
\text { Exploitations de } \\
\text { production de masse } \\
\text { en début d'intensifi- } \\
\text { cation }(30 \%)\end{array}$ & $\begin{array}{l}\text { - Outils trainés } \\
\text { - Pas de binage }\end{array}$ & $\begin{array}{l}10 \\
(0 ; 35) \\
{[20 \%]}\end{array}$ & $\begin{array}{l}-(\mathrm{Mf}-\mathrm{BI}-\mathrm{O})_{[3-6]^{-}}-\mathrm{PT}_{[4-6]} \\
-\mathrm{Mf}_{[2-3]^{-B I}-\mathrm{O}-\mathrm{PT}_{[2]}} \\
-\mathrm{Mf}_{[2-5]^{-} \mathrm{BI}-\mathrm{O} \text { ou mono- }} \\
\text { culture de mais fourrager }\end{array}$ & $\begin{array}{l}\text { Production de foin, base de } \\
\text { l'alimentation des vaches laitières } \\
\text { Parcelles proches des bâtiments } \\
\text { ou humides } \\
\text { Production de maïs fourrager sur } \\
\text { parcelles proches des bâtiments }\end{array}$ \\
\hline $\begin{array}{l}\text { INT } \\
\text { Exploitations de } \\
\text { production de masse } \\
\text { intensives }(25 \%)\end{array}$ & $\begin{array}{l}\text { - Outils animés } \\
\text { - Semis en combiné } \\
\text { fréquent } \\
\text { - Binage fréquent }\end{array}$ & $\begin{array}{l}45 \\
(23 ; 95) \\
{[56 \%]}\end{array}$ & 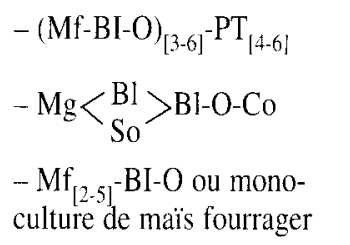 & $\begin{array}{l}\text { Production de foin dans les } \\
\text { Exploitations céréalières } \\
\text { Production de mais fourrager sur } \\
\text { parcelles proches des bâtiments, } \\
\text { dans les exploitations laitières }\end{array}$ \\
\hline $\begin{array}{l}\text { DVA } \\
\text { Exploitations } \\
\text { diversifiées (11\%) }\end{array}$ & $\begin{array}{l}\text { - Outils animés } \\
\text { - Semis combiné } \\
\text { fréquent } \\
\text { - Binage fréquent }\end{array}$ & $\begin{array}{l}26 \\
(6 ; 62) \\
{[17 \%]}\end{array}$ & $-\mathrm{Mg}<\begin{array}{l}\mathrm{Bl} \\
\mathrm{SO}_{0}\end{array}>\mathrm{Bl}-\mathrm{O}-\mathrm{CO}$ & $\begin{array}{l}\text { Atelier céréalier complémentaire } \\
\text { de productions à valeur ajoutée }\end{array}$ \\
\hline $\begin{array}{l}\text { CO } \\
\text { Exploitations } \\
\text { commercialisatrices } \\
(13 \%)\end{array}$ & $\begin{array}{l}\text { - Outils animés } \\
\text { - Semis en combiné } \\
\text { fréquent } \\
\text { - Binage fréquent }\end{array}$ & $\begin{array}{l}1,7 \\
(1 ; 3) \\
{[2 \%]}\end{array}$ & $-\mathrm{Mg}<\underset{\mathrm{So}}{\mathrm{Bl}}>\mathrm{Bl}-\mathrm{O}-\mathrm{Co}$ & Atelier céréalier résiduel \\
\hline
\end{tabular}

Mg : maïs grain ; Mf : maïs fourrager ; Bl : blé d'hiver ; Or : orge ; Be : betterave fourragère ; So : soja ; Co : colza fourrager ; PT : prairie temporaire ; [nombre d'années]. 
l'assolement. Les retours de maïs dans les rotations sont assez fréquents.

Les exploitations «en début d'intensification » (DI) relèvent de logiques de capitalisation de l'outil de production, qui conduisent à l'augmentation du cheptel et des surfaces des cultures fourragères. Près de $40 \%$ de l'assolement est consacré à l'alimentation du troupeau (blé, orge et maïs fourrager). Dans la plupart des cas, le maïs fourrager est implanté avec des retours fréquents (voire en monoculture), sur des parcelles proches des sièges d'exploitation pour faciliter les travaux de récolte et d'épandage de matière organique.

Les exploitations « intensives » (INT), laitières et/ou céréalières, se situent dans une logique de production de masse. Ce fonctionnement montre une extension des cultures annuelles (70\% de l'assolement), au détriment des prairies naturelles : plus de la moitié des surfaces de cultures annuelles de la zone est cultivée par ce type d'exploitation. L'extension des surfaces de cultures annuelles permet de réduire la fréquence des retours du maïs (ou des autres cultures fourragères comme les betteraves et le colza), sauf sur quelques parcelles proches des sièges d'exploitation où la quasi-monoculture de maïs fourrager persiste. L'utilisation d'outils animés et le recours fréquent au binage caractérisent également ce fonctionnement.

Les exploitations « diversifiées à valeur ajoutée " (DVA) se distinguent par un important noyau de cultures de vente (blé meunier, soja, maïs grain), qui occupe $70 \%$ de l'assolement, et fait l'objet de techniques de production intensives. Cet atelier est complémentaire d'un atelier à valeur ajoutée (vigne, petits fruits, maraîchage ou pépinière) qui constitue généralement la principale ressource de l'exploitation. Enfin, les exploitations « commercialisatrices » $(\mathrm{CO})$ ont une activité basée sur la valorisation de produits à forte valeur ajoutée, dont elles maîtrisent la transformation et la commercialisation. Les cultures annuelles sont très secondaires ( $20 \%$ de l'assolement) et tendent même à être abandonnées.

\section{Démarche}

\section{Choix des parcelles de suivi}

Deux ensembles de parcelles de cultures annuelles caractéristiques de la diversité des « situations culturales » font l'objet des suivis des symptômes du ruissellement, l'un pendant la période hivernale, l'autre pendant la période printanière. Par situa- tion culturale, on entend une période comprise entre le semis et la récolte pour les cultures, ou entre la récolte de la culture précédente et le labour dans le cas des intercultures.

Durant l'hiver (octobre 1993 - mars 1994), le suivi porte sur 97 parcelles représentatives des situations culturales présentes en hiver, des conditions d'implantation des cultures, des précédents culturaux et des caractéristiques texturales (tableau II). Dans le cas du suivi estival (avril 1994 - septembre 1994), 72 parcelles sont étudiées (tableau III), principalement des cultures de maïs, avec divers précédents culturaux, textures, et modalités d'implantation.

Les combinaisons de pratiques effectivement mises en œuvre par l'exploitant durant la saison de l'étude sont connues par enquête. Chaque parcelle fait l'objet de prélèvements de terre $(0-30 \mathrm{~cm})$ pour analyse granulométrique. Leur surface n'excède jamais 2 ha, avec des pentes variables, mais inférieures à $5 \%$. La pluviosité des périodes de suivi est connue à partir des données pluviométriques de la station voisine de Thonon-les-bains (380 m ; fig 1).

\section{Suivi de la dégradation de la structure superficielle et des symptômes de ruissellement}

Selon les travaux de Boiffin (1984), le recours à un système de notation basé sur des descripteurs de l'infiltrabilité et de la détention superficielle de l'eau, permet d'apprécier les évolutions de la battance et les différences entre les parcelles. Ces descripteurs sont de type qualitatif ordonné. Ils sont relevés par un même observateur, après chaque événement pluvieux, soit en moyenne toutes les trois semaines (fig 2).

Les descripteurs de l'infiltrabilité sont le stade de développement des croûtes de battance et le pourcentage de la surface du sol affecté par les empreintes de roues non effacées. Le développement des croûtes de battance est apprécié par référence à des faciès structuraux types $(F 0, F 1$ et $F 2)$ qui apparaissent progressivement sous l'action des pluies cumulées. Au faciès $F 2$ peut succéder un faciès $F 3$, dû au remaniement des croûtes sous l'effet des agents climatiques ou biologiques. Le passage du faciès $F 0$ à $F 1$, puis à $F 2$, s'accompagne d'une baisse de l'infiltrabilité des premiers centimètres du sol. Dans le cas des sols limoneux, l'infiltrabilité est comprise entre 30 et $50 \mathrm{~mm} \cdot \mathrm{h}^{-1}$ pour $F 0,5$ et $30 \mathrm{~mm} \cdot \mathrm{h}^{-1}$ pour $F 1$ et $1-2 \mathrm{~mm} \cdot \mathrm{h}^{-1}$ pour $F 2$ (Boiffin et al, 1988). Avec F3, la perméabilité de surface reprend des valeurs élevées, qu'il est toutefois difficile d'évaluer précisément. 
Tableau II. Dispositif de suivi de la période hivernale ( $n=$ nombre de parcelles suivies).

\begin{tabular}{|c|c|c|c|}
\hline \multicolumn{4}{|c|}{ Critères de sélection } \\
\hline Modes d'occupation du sol & Travail du sol & Précédent, rotation & Texture \\
\hline $\begin{array}{l}\text { Semis de céréales } \\
n=56\end{array}$ & $\begin{array}{l}-30 \text { sous outils } \\
\text { animés dont } 18 \text { sous } \\
\text { semis combiné } \\
-26 \text { sous outils } \\
\text { non animés }\end{array}$ & $\begin{array}{l}-37 \text { après céréales à } \\
\text { paille } \\
-19 \text { après maïs grain } \\
-24 \text { inclus dans des rotations } \\
\text { où le retour de maïs } \leq 15 \% \\
-16 \text { où retour de maïs }>15 \% \\
\text { et } \leq 30 \% \\
-16 \text { où retour de maïs }>30 \%\end{array}$ & $\begin{array}{l}-6 \text { de texture « lourde } \\
-41 \text { de texture } \\
\text { « intermédiaire » } \\
-9 \text { de texture « légère }\end{array}$ \\
\hline $\begin{array}{l}\text { Chantiers de récolte non } \\
\text { repris par un travail du sol } \\
n=19\end{array}$ & & $\begin{array}{l}-6 \text { après céréales à paille } \\
-7 \text { après maïs grain } \\
-4 \text { après maïs fourrager } \\
-2 \text { après betterave }\end{array}$ & $\begin{array}{l}\text { - Texture « intermédiaire » } \\
\text { sur céréales à paille } \\
\text { - Textures non déterminées } \\
\text { sur autres chantiers } \\
\text { de récolte }\end{array}$ \\
\hline $\begin{array}{l}\text { Chantiers de récolte repris } \\
\text { par un travail du sol } \\
n=18\end{array}$ & $\begin{array}{l}-6 \text { échaumages tardifs } \\
-12 \text { échaumages } \\
\text { précoces }\end{array}$ & - 18 après céréale à paille & $\begin{array}{l}\text { - } 18 \text { de texture } \\
\text { «intermédiaire » }\end{array}$ \\
\hline $\begin{array}{l}\text { Cultures dérobées } \\
n=4\end{array}$ & $\begin{array}{l}-2 \text { colzas fourragers } \\
\text { fauchés } \\
-2 \text { colzas fourragers } \\
\text { pâturés }\end{array}$ & - 4 après céréales à paille & $\begin{array}{l}\text { - } 4 \text { de textures } \\
\text { « intermédiaires » }\end{array}$ \\
\hline
\end{tabular}

Tableau III. Dispositif de suivi de la période estivale $(n=$ nombre de parcelles suivies).

\begin{tabular}{|c|c|c|c|}
\hline \multicolumn{4}{|c|}{ Critères de sélection } \\
\hline Modes d'occupation du sol & Travail du sol & Précédent, rotation & Texture \\
\hline $\begin{array}{l}\text { Semis de maïs } \\
n=53\end{array}$ & $\begin{array}{l}-33 \text { labours d'hiver } \\
-20 \text { labours de } \\
\text { printemps } \\
-15 \text { sous-semis } \\
\text { combiné } \\
-38 \text { sous-semis non } \\
\text { combiné } \\
-22 \text { binés } \\
-31 \text { non binés }\end{array}$ & $\begin{array}{l}-26 \text { après céréales à paille } \\
-22 \text { après maïs } \\
-5 \text { après prairie } \\
-24 \text { inclus dans des rotations } \\
\text { où le retour de maïs } \leq 15 \% \\
-24 \text { où retour de maïs }>15 \% \\
\text { et } \leq 30 \% \\
-6 \text { où retour de maïs }>30 \%\end{array}$ & $\begin{array}{l}-9 \text { de texture « lourde » } \\
-31 \text { de texture } \\
\text { «intermédiaire » } \\
-13 \text { de texture « légère » }\end{array}$ \\
\hline $\begin{array}{l}\text { Semis de céréales } \\
\text { de printemps } \\
n=11\end{array}$ & $\begin{array}{l}-3 \text { labours d'hiver } \\
-8 \text { labours de } \\
\text { printemps } \\
-5 \text { sous-semis combiné } \\
-6 \text { sous-semis non } \\
\text { combiné }\end{array}$ & $\begin{array}{l}-5 \text { après céréales à paille } \\
-4 \text { après maïs } \\
-2 \text { après prairie }\end{array}$ & $\begin{array}{l}-7 \text { de texture } \\
\text { « intermédiaire » } \\
-4 \text { de texture « légère » }\end{array}$ \\
\hline $\begin{array}{l}\text { Semis de betteraves } \\
\text { fourragères } \\
n=5\end{array}$ & $\begin{array}{l}-3 \text { labours d'hiver } \\
-2 \text { labours de } \\
\text { printemps } \\
-5 \text { sous-semis non } \\
\text { combiné } \\
-3 \text { binés } \\
-2 \text { non binés }\end{array}$ & $\begin{array}{l}\text { - } 4 \text { après céréales à paille } \\
-1 \text { après prairie }\end{array}$ & $\begin{array}{l}-5 \text { de texture } \\
\text { «intermédiaire }\end{array}$ \\
\hline $\begin{array}{l}\text { Cultures de soja } \\
n=3\end{array}$ & $\begin{array}{l}-3 \text { labours d'hiver } \\
-2 \text { semis roulés } \\
-1 \text { semis non roulé }\end{array}$ & $\begin{array}{l}-2 \text { après maïs } \\
-1 \text { après soja }\end{array}$ & $\begin{array}{l}-3 \text { de texture } \\
\text { « intermédiaire }\end{array}$ \\
\hline
\end{tabular}




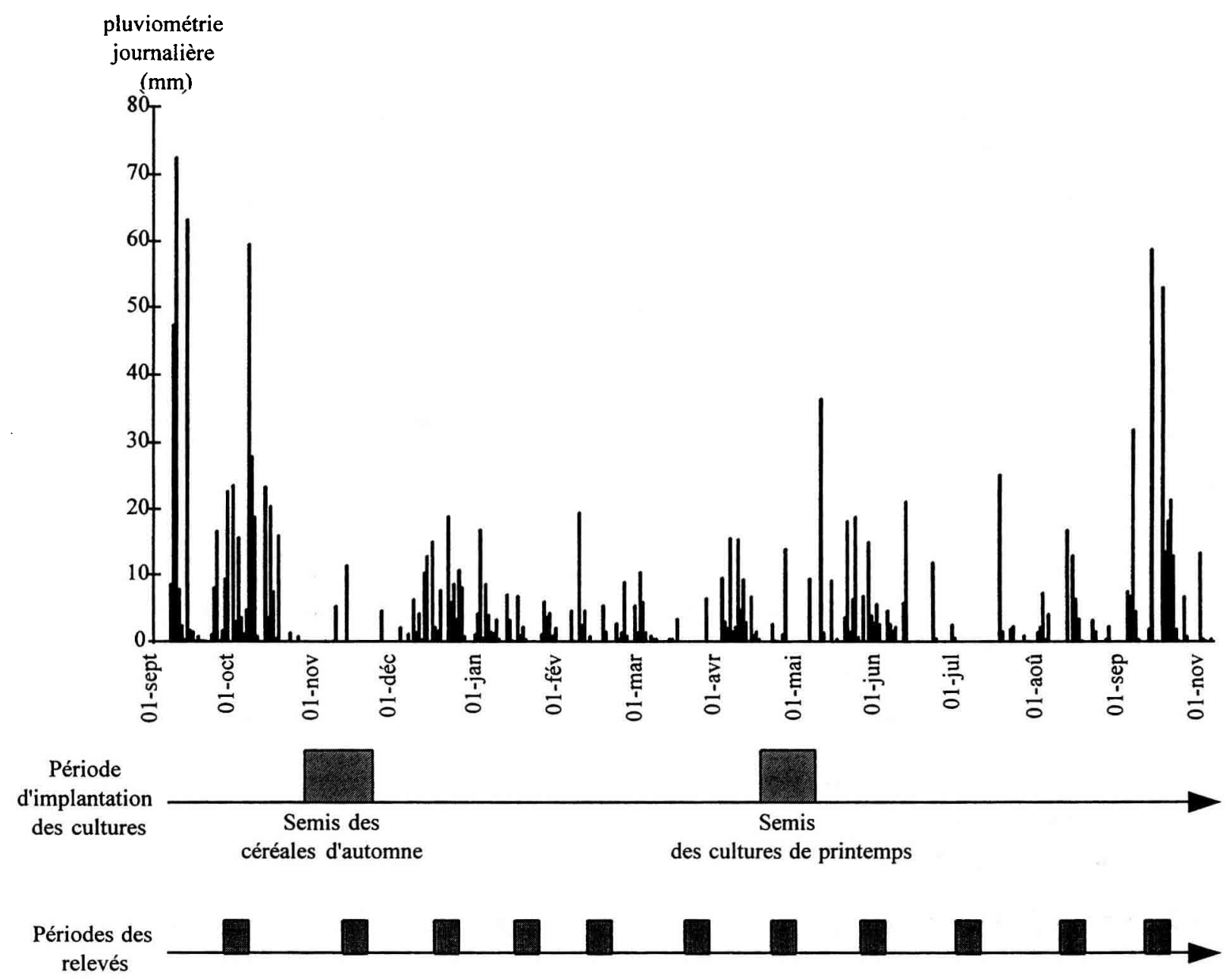

Fig 2. Pluviométrie journalière enregistrée pendant l'année de suivi. Périodes d'implantation des céréales d'automne, des cultures de printemps et dates des relevés.

La détention superficielle, ou capacité de stockage temporaire de l'eau à la surface du sol, est évaluée en appréciant la hauteur moyenne des dépressions de la surface du sol $(\mathrm{cm})$.

Parallèlement, on enregistre la date d'apparition des premiers signes du ruissellement, qui se manifestent par des réorganisations des débris organiques le long des pentes, des incisions et des griffures de la surface du sol ou des sédimentations de terre en bas de pente. D'autres symptômes, tels que les amas d'agrégats organisés par les écoulements, sont révélateurs du ruissellement au niveau des traces de roues. On se reportera aux références précédentes, ainsi qu'à Ludwig (1992) pour de plus amples détails sur la méthode de suivi.

\section{Traitement des données}

Les données concernant la date d'apparition et les modalités du ruissellement dans les divers types de parcelles étudiées sont mises en relation avec des variables caractéristiques du milieu physique et des pratiques agricoles. Afin d'établir la hiérarchie des facteurs de ruissellement, ces relations sont analysées par le test de Cocran-MantelHaenszel (FREQ/CMH, Sas System $\odot$ ), qui permet de détecter, pour des échantillons de petite taille, l'existence d'une corrélation entre deux variables.

\section{RÉSULTATS ET DISCUSSION}

\section{Calendriers culturaux et pluviométrie de la période étudiée}

Durant les suivis, la pluviométrie cumulée est légèrement supérieure à la moyenne des 25 dernières années, avec des excédents de $60 \mathrm{~mm}$ 
$(+10 \%)$ et de $100 \mathrm{~mm}(+25 \%)$, respectivement pour la période hivernale et estivale. Les semis s'effectuent pendant des périodes peu pluvieuses (fig 2), et, en conséquence, on peut considérer que l'histoire hydrique des différentes parcelles est similaire.

\section{Étude du ruissellement à l'échelle parcellaire}

\section{Types de ruissellement}

Les suivis révèlent que $50 \%$ des parcelles étudiées ne présentent pas de symptômes de ruissellement. Quand il existe, le ruissellement prend des formes diverses, quelle que soit la pente des parcelles (tableau IV) :

- diffus sur l'ensemble de la surface des parcelles ;

- localisé dans les traces de roues non effacées ;

- localisé dans les bas de versant à caractère hydromorphe ;

- d'origine « externe » résultant de débordement de fossés ou de ruisseaux.

Le ruissellement diffus ne provoque pas d'incisions ; il se manifeste par des traces liées à l'écoulement de filets d'eau et par des plaquages sédi- mentaires d'extension variable en bas de parcelle. Du fait de la faible dimension des parcelles et de la forte densité du réseau de fossé, le ruissellement diffus ne se concentre pas au sein des parcelles, contrairement à ce qui est observé dans le contexte du Bassin parisien (Papy et Douyer, 1991 ; Ludwig, 1992) ou du Plateau suisse (Mosimann et al, 1981). Pour ces mêmes raisons, le ruissellement issu des tassements localisés (traces de roues résultant des opérations de semis, de récolte, d'épandages de fertilisants ou phytosanitaires) n'acquiert pas une force tractrice suffisante pour inciser le sol. La faible force tractrice des écoulements caractérise également le ruissellement localisé dans les bas de versant.

En fait, les seules traces d'incisions repérées se rapportent au cas de ruissellement d'origine externe à la parcelle. Cette dernière forme de ruissellement, peu mentionnée dans la littérature, est fréquente dans le contexte étudié, du fait du mitage du parcellaire par l'urbanisation et de la densification du réseau de fossés routiers.

Les ruissellements de bas de versant, dont les extensions sont liées au débit de base nappe-ruisseau (Merot, 1991), et ceux d'origine externe, répondent à des déterminismes et des moyens de contrôle spécifiques, relevant de l'aménagement

Tableau IV. Types de ruissellement observés par occupation de sol.

\begin{tabular}{|c|c|c|c|c|c|}
\hline \multirow[b]{2}{*}{$\begin{array}{l}\text { Situations } \\
\text { culturales }\end{array}$} & \multicolumn{5}{|c|}{ Type de ruissellement observé } \\
\hline & $\begin{array}{l}\text { Ruissellement } \\
\text { diffus }\end{array}$ & $\begin{array}{l}\text { Ruissellement } \\
\text { localisé dans } \\
\text { les traces } \\
\text { de roues }\end{array}$ & $\begin{array}{c}\text { Ruissellement } \\
\text { localisé dans } \\
\text { les bas de } \\
\text { versant }\end{array}$ & $\begin{array}{c}\text { Ruissellement } \\
\text { «externe " }\end{array}$ & $\begin{array}{l}\text { Pas de } \\
\text { ruissellement } \\
\text { observé }\end{array}$ \\
\hline
\end{tabular}

\section{Période hivernale}

Chantiers de récolte non repris par un travail du sol après :

\footnotetext{
- céréales $(n=6)$

- maïs grain $(n=7)$

- maïs fourrager $(n=4)$

- betteraves $(n=2)$
}

$\begin{array}{cc}0 & 1 \\ 0 & 2 \\ 4 \text { avec diffus et localisé } \\ 2 \text { avec diffus et localisé }\end{array}$

0

0

0

0

$\begin{array}{ll}0 & 5 \\ 0 & 5 \\ 0 & 0 \\ 0 & 0\end{array}$

Chantiers de récolte repris par un travail du sol après céréales $(n=8)$

Colza fourrager $(n=4)$

Céréales d'hiver $(n=56)$

$\begin{array}{ccc}0 & & 5 \\ 16 & 4 & 0\end{array}$

0

\section{Période estivale}

Culture de maïs $(n=53)$

Culture de betteraves $(n=5)$

Céréales de printemps $(n=11)$

Culture de soja $(n=3)$

$\begin{array}{cc}15 & 16 \\ 5 \text { avec diffus et localisé } \\ 0 & 2 \\ 2 & 0\end{array}$

0

0

0

0

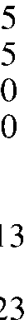

.

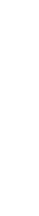


des bassins. Ils se situent en grande partie en dehors du champ d'action des pratiques agricoles et nous avons donc centré la suite de notre travail sur le ruissellement diffus ou localisé dans les traces de roues.

\section{Conditions d'apparition du ruissellement diffus ou lié aux traces de roues}

\section{Cas des chantiers de récolte}

Les sols après récolte, non repris par un travail, peuvent présenter à la fois des symptômes de ruissellement diffus et de ruissellement localisé dans les traces de roues (tableau IV). Lorsqu'ils sont labourés, déchaumés ou quand il subsiste, comme pour les maïs grain, une importante couche de résidus végétaux, le ruissellement diffus ne se manifeste pas et les seuls cas de ruissellement sont alors liés aux traces de roues provenant d'épandages hivernaux de matière organique. Sous les résidus végétaux, il existe dès le début de l'automne et tout au long de l'hiver, des faciès de remaniements $F 3$ qui résultent principalement de l'activité des vers de terre.

La forte sensibilité au ruissellement des chantiers de récolte, déjà décrite par Boiffin et al, 1988 ; Papy et Douyer, 1991 ; Mosimann et al, 1991, se confirme donc dans le contexte étudié. Seuls la présence d'une importante couche de résidus ou le déchaumage, s'accompagnent d'une amélioration de l'infiltrabilité du sol, ce qui réduit la sensibilité au ruissellement.

\section{Cas des semis d'automne ou de printemps}

Les semis montrent une grande diversité de sensibilité au ruissellement (tableau IV).

Le ruissellement localisé dans les traces de roues concerne principalement les semis de maïs et de betterave. Il apparaît très rapidement après les travaux de semis, d'épandage de produits phytosanitaires ou de fertilisants. En dehors des traces de roues, l'état de surface est dominé par des faciès $F 0$ et $F 1$ et aucun signe d'écoulement n'est observé.

Le ruissellement diffus, lorsqu'il se manifeste, apparaît ultérieurement. Certaines cultures ne ruissellent pas (blé et orge de printemps), alors que d'autre (betterave et soja) ruissellent systématiquement. D'autres enfin, ruissellent parfois (céréales d'automne et semis de maïs).

Dans ce dernier cas, le ruissellement diffus est observé plus ou moins précocement après le semis. Pour les céréales d'automne, il apparaît dans les conditions de l'étude, après des pluies cumulées soit de $80 \mathrm{~mm}$ environ (ruissellement dit «précoce 》) soit de $180 \mathrm{~mm}$ (ruissellement «tardif »). Pour le maïs, le ruissellement précoce correspond à une pluviométrie cumulée de $175 \mathrm{~mm}$ et le ruissellement tardif à $280 \mathrm{~mm}$.

Quelle que soit la saison culturale considérée et la précocité du ruissellement, on constate que les écoulements diffus se déclenchent toujours, lorsqu'au moins $40 \%$ de la surface du sol est recouverte par une croûte sédimentaire $F 2$ (fig 3 ). L'augmentation du taux de recouvrement de la surface par les croûtes sédimentaires s'accompagne toujours d'une diminution parallèle de la rugosité (fig 4) : à l'extrême, les valeurs maximales de $F 2$ et les valeurs minimales de rugosité observées sont respectivement de $80 \%$ et de $1 \mathrm{~cm}$. Le couplage entre ces deux phénomènes est bien connu : l'action des pluies se traduit simultanément par une diminution de la capacité de détention de l'eau à la surface et de la capacité d'infiltration des premiers centimètres du sol (Boiffin, 1984, Le Bissonnais, 1990). Lorsque la structure superficielle des sols atteint un stade de dégradation suffisant (dans les conditions de l'étude, $40 \%$ de F2), les flaques qui apparaissent dans les microdépressions peuvent se connecter entre elles, ce qui conduit au ruissellement. Ce stade de dégradation, nommé faciès de déclenchement du ruissellement, est atteint plus ou moins rapidement, d'où des ruissellements diffus plus ou moins précoces. Dans la mesure où, lors de notre étude, l'histoire hydrique des parcelles étudiées est identique, ce sont des différences de pratique ou de milieu qui expliquent la variabilité des réponses.

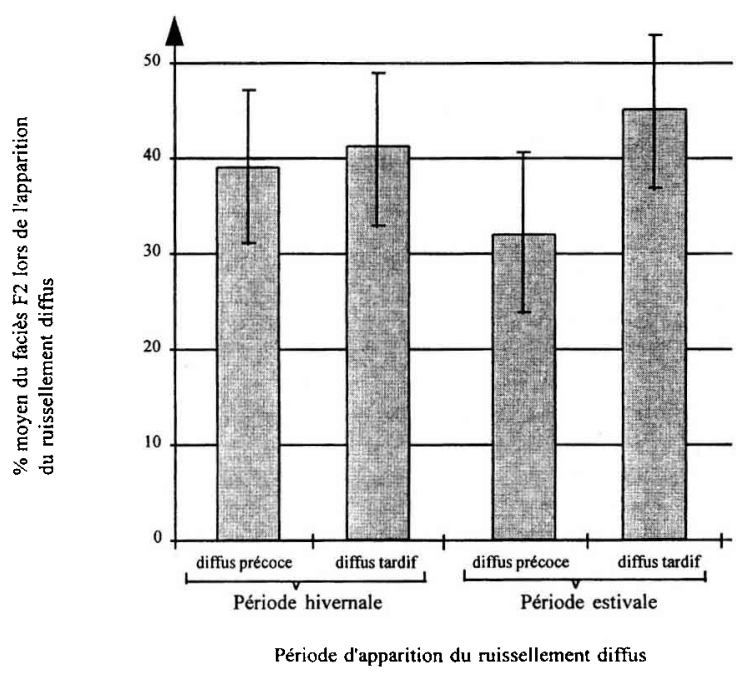

Fig 3. Proportion moyenne des surfaces $F 2$ observée à l'apparition du ruissellement diffus. Les barres donnent l'écart type. 


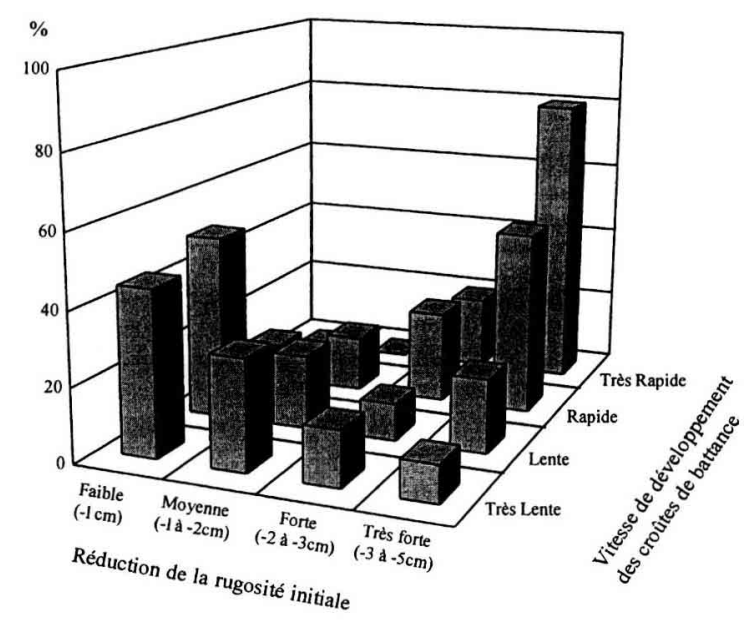

Fig 4. Cas des cultures de maïs : vitesses d'évolution des croûtes de battance et réduction de rugosité (différences des valeurs moyennes des dépressions entre début et fin de suivi) dans le cas des cultures de maïs. (Cinétique très rapide : proportion maximale de $F 2$ de $80 \%$ après $80 \mathrm{~mm}$ de pluie succédant au semis, cinétique rapide : $80 \%, 250 \mathrm{~mm}$; cinétique lente : $30 \%, 250 \mathrm{~mm}$; cinétique très lente : $10 \%, 300 \mathrm{~mm}$.)

\section{Facteurs de contrôle du ruissellement diffus ou localisé dans le cas des semis}

Les variables prises en compte dans cette analyse sont les caractéristiques texturales, les modalités d'implantation de la culture, l'état initial des lits de semence, les pratiques liées à l'entretien des cultures et les précédents culturaux.

\section{Céréales d'automne}

Le nombre de passage d'outil lors de la préparation des lits de semence influe de façon très significative sur l'apparition du ruissellement diffus $(p<0,001$, tableau V) : plus les passages sont nombreux, plus la proportion de parcelles ruisselantes est élevée. L'augmentation du nombre de passage se traduit par un affinement des lits de semence, significativement corrélé à l'apparition du ruissellement $(p=0,029)$. Le type d'outil, qui conditionne le nombre de passage, est également lié au ruissellement $(p=0,008)$. Cet effet travail du sol doit cependant être nuancé en fonction des précédents culturaux : avec un précédent céréale, fréquence et précocité du ruissellement s'accroissent progressivement avec le nombre de passage d'outil $(p=0,02)$, ce qui n'est pas le cas avec un précédent maïs $(p=0,062)$. En fait pour les précédents maïs, fréquence et précocité du ruissellement augmentent nettement dès deux passages d'outil $(p=0,008)$. Enfin, la texture n'est pas liée significativement au ruissellement $(p=0,471)$.

Tableau V. Résultats du suivi hivernal des semis de céréales d'automne.

\begin{tabular}{|c|c|c|c|}
\hline $\begin{array}{l}\text { Nombre de } \\
\text { passages d'outil }\end{array}$ & Type de semis & Précédent cultural & Texture \\
\hline
\end{tabular}

Pas de ruissellement

1 passage : $15^{*}$

2 passages : 12

3 passages : 10

4 passages : 3

\section{Ruissellement tardif}

1 passage : 0

2 passages : 3

3 passages : 2

4 passages : 4

\section{Combiné : 18}

Non combiné : 22

Combiné : 0

Non combiné : 9

Ruissellement précoce

1 passage : 0

2 passages : 0

3 passages : 3

4 passages : 4
Céréales paille : 30 Maïs : 10
Lourde : 6 Intermédiaire : 28

Légère : 6

$p<0,001$

$$
p=0,008
$$

$p=0,088$

Lourde : 0 Intermédiaire : 8 Légère : 1

Nombre de parcelles ayant ou non ruissellé selon les pratiques de travail du sol, le précédent cultural et la texture de surface ( $p$ donne le résultat du test $\mathrm{CMH}$; lorsque $p<0,01$, il y a corrélation hautement significative entre précocité du ruissellement et la variable testée : lorsque $p<0,05$, la corrélation est significative). ${ }^{*} n=$ nombre de parcelles. 


\section{Cas des semis de printemps}

La texture de l'horizon de surface n'est liée ni au ruissellement diffus $(p=0,351)$ ni au ruissellement localisé dans les traces de roue $(p=0,587)$. À nouveau, fréquence et précocité du ruissellement sont associées à certaines pratiques de travail du sol.

Le ruissellement localisé dans les traces de roues ne peut apparaître sur les parcelles que lorsque les interventions culturales marquent la surface du sol. C'est le cas des semis effectués avec un passage de semoir distinct de la préparation du lit de semence (50\% des parcelles ont des ruissellements localisés), ou après semis avec outils combinés, lorsque des traces de roues sont rajoutées par des travaux d'entretien de la culture de maïs (dans ces conditions tous les semis combinés ruissellent, alors qu'aucun n'est affecté sans entretien postsemis).

L'apparition du ruissellement diffus n'est reliée de façon significative qu'avec le précédent cultural, le type de semis et le nombre de passages (tableau VI). L'influence du précédent cultural se manifeste par l'apparition quasi systématique du ruissellement diffus, si le maïs est semé après une prairie temporaire. Ainsi $80 \%$ des maïs après prairie ruissellent. Avec ce précédent, les lits de semence réalisés sont particulièrement fins $(p<0,001): 60 \%$ des parcelles ont des éléments structuraux de taille inférieure à $1 \mathrm{~cm}$ (pour les autres précédents, cette proportion n'est que de 25 $\%)$.

L'influence du type de semis est également très significative puisqu'aucun ruissellement diffus n'est constaté après semis en combiné, alors que la moitié des parcelles ruissellent pour des semis en non-combiné. Dans ce dernier cas, la fréquence d'apparition du ruissellement est d'autant plus forte que le taux de retour du maïs dans la rotation est élevée $(p<0,001)$. À l'extrême, avec des retours très fréquents (au moins un maïs sur 3 ans), l'apparition du ruissellement diffus est systématique.

Enfin, le ruissellement de type diffus ou localisé dans les traces de roues est définitivement stoppé par le binage des parcelles.

\section{Synthèse}

Dans la zone d'étude, les sols ont une assez forte proportion d'argile et de matière organique et, en conséquence, une assez grande résistance à la dégradation sous l'effet des pluies (Le Bissonnais, 1988). Dans ces conditions, l'effet des pratiques devient prépondérant. L'absence de relation nette entre sensibilité à la dégradation de surface et

Tableau VI. Résultats du suivi estival des semis de maïs.

\begin{tabular}{|c|c|c|c|}
\hline $\begin{array}{l}\text { Nombre de } \\
\text { passages d'outil }\end{array}$ & Type de semis & Précédent cultural & Texture \\
\hline
\end{tabular}

Pas de ruissellement

$\leq 2$ passage : $12 *$

$>2$ passages : 26

Ruissellement tardif

$\leq 2$ passage : 1

$>2$ passages : 10

Combiné : 0

Non combiné : 11

Prairie : 1
Céréales paille $: 22$
Maïs : 15

Maîs : 15

Prairie : 3

Céréales paille : 4

Maïs : 4
Lourde : 6 Intermédiaire : 27

Légère : 5

\section{Ruissellement précoce}

$\leq 2$ passage : 0

$>2$ passages : 4

Combiné : 0

Non combiné : 4

$p=0,001$
Prairie : 3

Céréales paille : 1

Maïs : 0

$p=0,001$
Lourde : 2

Intermédiaire : 8

Légère : 1

$p<0,001$

Nombre de parcelles ayant ou non ruissellé selon les pratiques de travail du sol, le précédent cultural et la texture de surface ( $p$ donne le résultat du test $\mathrm{CMH}$; lorsque $p<0,01$, il y a corrélation hautement significative entre précocité du ruissellement et la variable testée ; lorsque $p<0,05$, la corrélation est significative). ${ }^{*} n=$ nombre de parcelles. 
JY Vansteelant et al

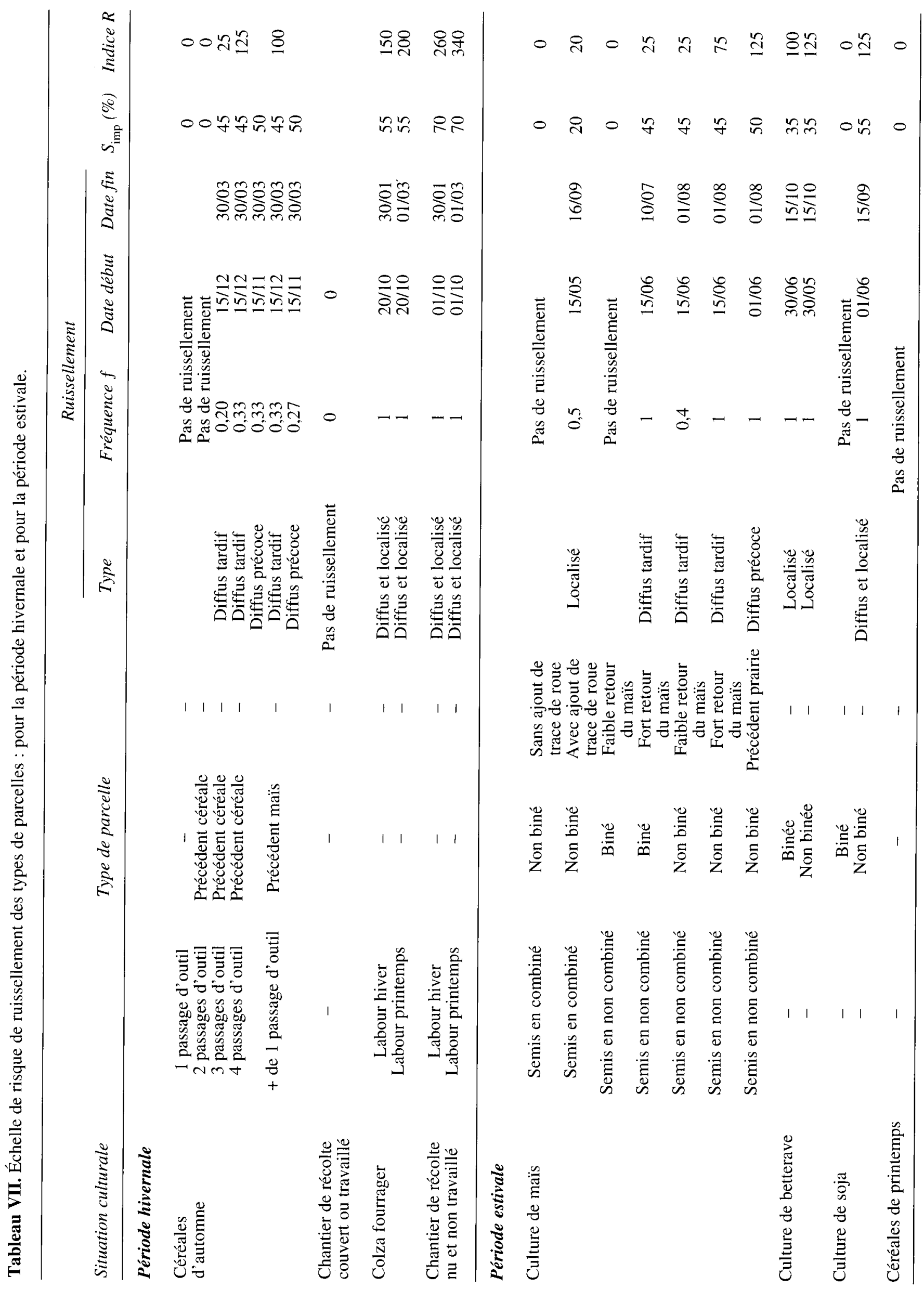


caractéristiques texturales est également soulignée par Auzet et al, 1990, dans des contextes où les pratiques culturales engendrent toute une gamme d'états structuraux des horizons labourés.

Dans le Bas-Chablais, certaines pratiques accroissent les risques de ruissellement.

Les outils non animés, le semis avec des outils non combinés ou le roulage, tels qu'ils sont utilisés dans la région, conduisent à la fois à un affinement poussé et une rugosité faible du lit de semence, ce qui facilite la dégradation de l'état de surface et le déclenchement du ruissellement diffus (Boiffin, 1984).

De même, l'augmentation du nombre de passage, l'implantation d'une culture après un chantier de récolte de maïs ou de betterave, ou la répétition des récoltes de maïs dans la rotation augmentent probablement les tassements superficiels qui, en limitant l'infiltration de l'eau, augmentent la fréquence des écoulements de surface. Les tassements et ruissellements systématiques observés après fauche ou pâture hivernale du colza relativisent l'effet bénéfique généralement admis de cette culture dérobée pour la protection des sols et de l'eau (Mosimann et al, 1991). Enfin, le recours à un outillage marquant la surface du sol (semis en non combiné) ainsi que les travaux d'entretien des cultures ou d'épandage de matière organique sont à l'origine de ruissellements localisés.

Le précédent prairie aboutit à des dégradations rapides de la structure superficielle du sol. Ce résultat est assez surprenant, compte tenu de l'amélioration bien connue des propriétés structurales sous prairie (Marty et Fioramonti, 1970 ; Bui Huu Tri et Monnier, 1973). Mais le comportement observé suggère que le poids du facteur stabilité structurale est secondaire par rapport à celui de la taille des mottes initiales.

Si dans le contexte étudié, certaines pratiques sont pénalisantes, on note à l'inverse un ensemble de phénomènes ou de pratiques qui recréent une forte perméabilité de surface ou protègent le sol de l'impact des gouttes de pluies et empêchent ainsi l'apparition du ruissellement. C'est le cas de l'activité des vers de terre, du déchaumage, du binage, de la colonisation rapide du sol par la végétation des blés et orges de printemps ou encore, de la présence d'un mulch de résidus de culture.

Tous ces résultats montrent qu'il n'est pas possible d'attribuer un risque de ruissellement à une situation culturale donnée, mais qu'il faut distinguer des «types de parcelles » tenant compte de « l'historique » des situations culturales, c'est-à- dire des précédents culturaux et des combinaisons de pratiques de travail du sol mises en œuvre lors de la préparation des lits de semences.

\section{Étude comparée des risques de ruissellement selon le fonctionnement des exploitations agricoles}

Pour étudier les relations entre fonctionnement des systèmes d'exploitation et ruissellement, nous avons choisi de condenser et d'ordonner les connaissances acquises sous la forme d'indices permettant de classer les risques de ruissellement pour les différents types de parcelles (combinaisons de pratiques et précédents des situations culturales); et les différents systèmes d'exploitations agricoles.

\section{À l'échelle de la parcelle agricole}

Le risque de ruissellement à l'échelle de la parcelle tient compte :

- de la fréquence $f$ d'apparition du ruissellement de chaque type de parcelle ;

- de la pluviométrie moyenne de la période où les surfaces présentent des structures continues (Monnier et al, 1986), ce qui implique de définir les dates moyennes de début et de fin du ruissellement ;

- de la surface moyenne recouverte par les faciès peu perméables ( $F 2$ ou empreintes de roues).

\section{Fréquence d'apparition du ruissellement}

Pour les différents types de parcelle, on calcule une fréquence $f$ d'apparition du ruissellement (tableau VII) :

$$
f=\frac{n}{N}
$$

où $n$ est le nombre de parcelles ruisselantes et $N$ le nombre de parcelles suivies.

Ce ratio traduit l'existence d'une variabilité résiduelle non expliquée. Ainsi, par exemple, $33 \%$ des parcelles semées en céréales d'automne ne ruissellent pas, malgré un nombre de passages d'outil important. En fait, d'autres facteurs, non révélés ou non directement pris en compte, peuvent expliquer cette variabilité résiduelle. C'est le cas notamment des types et des conditions d'utilisation des appareils (vitesse d'avancement, profondeur de travail) qui peuvent influer sur le degré d'affinage du lit de semence. La répartition spatiale des intensités des pluies et la variabilité stationnelle des conditions pédologiques, peuvent aussi 
être en cause. L'intégration de tous ces facteurs est difficile à l'échelle définie par le cadre de cette étude, si bien que nous considérerons par la suite, qu'à une combinaison de pratique et un précédent donné, correspond une fréquence $f$ d'apparition du ruissellement.

\section{Dates de début et de fin des périodes de ruissellement}

Dans le cas des chantiers de récolte non repris par un travail du sol, la date du début de ruissellement correspond à celle de la récolte de la culture précédente. Dans le cas des semis d'automne et de printemps, le ruissellement diffus débute quand $40 \%$ de $F 2$ recouvre la surface du sol. Connaissant la hauteur de pluie cumulée nécessaire pour atteindre depuis le semis ce faciès de déclenchement, on peut calculer la date d'apparition du ruissellement en année moyenne (tableau VII). Ce calcul prend en compte la date habituelle des semis et la pluviométrie décadaire moyenne des 25 dernières années.

Selon les situations culturales, la date moyenne de fin du ruissellement correspond à la date habituelle de la récolte (betterave, soja, maïs), du binage (maïs), du labour des chantiers de récolte ou des colzas, ou de reprise de la végétation (céréales d'automne ; tableau VII). Ce sont les cultures d'automne qui présentent les périodes à risques les plus longues, avec, en moyenne, des ruissellements qui débutent vers début décembre et se poursuivent jusqu'à fin mars.

\section{Évaluation des surfaces moyennes imperméabilisées $\mathrm{S}_{i m p}$}

L'estimation des proportions de surface imperméabilisée est différente selon l'origine des imperméabilisations (tableau VII). Dans le cas du ruissellement diffus, pour tenir compte de l'extension des surfaces battues durant la période de ruissellement, nous avons approché la proportion moyenne de surface imperméabilisée $S_{\text {imp }}$ selon :

$$
S_{\text {imp }}=40 \%+\left(\begin{array}{c}
\% \text { de la surface ayant un } \\
\text { faciès } F 2 \text { à la date de fín } \\
\text { du ruissellement }-40 \% \\
2
\end{array}\right)
$$

Dans le cas du ruissellement localisé, $S_{\text {imp }}$ correspond à la valeur moyenne observée des surfaces des traces de roues. Lorsque les parcelles présentent à la fois des problèmes de dégradation et de tassement superficiel, les deux valeurs correspondantes sont sommées.

\section{Échelle de risque de ruissellement}

Pour chaque type de parcelle, un indice de ruissellement $R$ est calculé selon:

$$
R=\frac{1}{n} \sum_{1}^{n}\left(S_{\text {imp }} * f * P\right)
$$

où $n$ représente le nombre de parcelles suivies, $f$ la fréquence du ruissellement et $P$ la pluviométrie moyenne $(\mathrm{mm})$ entre le début et la fin de période de ruissellement.

En calculant cet indice $R$ pour chaque type de parcelle, on définit une échelle de risque relatif de ruissellement, avec des valeurs (tableau VII) :

- maximales $(R \geq 200)$ pour les chantiers de récolte nus et non repris par un travail du sol ainsi que pour le colza fourrager labouré au printemps ;

- moyennes $(R=100$ à 200) pour un ensemble de situations comprenant les céréales d'automne avec des nombres de passages d'outils élevés, le colza fourrager labouré fin janvier, les betteraves et soja non biné et le maïs après prairie ;

- plus modérés ( $R=25$ à 100) pour les céréales d'automne à nombre de passages d'outil moyen et pour les maïs semés en non combiné ;

- faibles $(R<25)$ pour les céréales d'automne à faible nombre de passages d'outil, les céréales de printemps, les maiis semés en combiné ou binés, les déchaumages de céréale et les chantiers de récolte couverts ou repris par un travail du sol.

\section{Risque de ruissellement et fonctionnements d'exploitation}

Le risque de ruissellement lié au fonctionnement d'un système d'exploitation peut être défini en premier lieu comme étant la proportion de la surface cultivée avec des pratiques à risque, ce qui revient à analyser la fréquence des pratiques à risques dans les systèmes. Mais, à l'échelle d'un vaste territoire pour définir un risque global lié à un fonctionnement d'exploitation, il faut également tenir compte de l'étendue des surfaces gérées par ce fonctionnement.

\section{Proportion de surface cultivée à risque de ruissellement $P \mathrm{~s}$}

Pour chaque type de parcelle $i$, elle peut être calculée selon :

$$
P S=\frac{\sum_{1}^{m}(S \mathrm{i} * f i)}{\sum_{i}^{m} S \mathrm{i}}
$$


où $m$ est le nombre d'exploitations enquêtées de chaque fonctionnement, $S i$ la surface des parcelles concernées et $f i$ la fréquence du ruissellement.

Le risque global $R$ t est donné par:

$$
R \mathrm{t}=\sum_{1}^{m}(S \mathrm{i} * R \mathrm{i})
$$

où $R i$ est l'indice du risque de ruissellement des divers types de parcelles.

Un exemple de calcul est donné dans le tableau VIII. Dans cet exemple, notez que les 12 ha de céréales d'automne de l'agriculteur 2 se trouvent en situation à risque de ruissellement 1 année sur 3, lorsque les céréales d'automne succèdent au maïs, d'où une surface à risque de 4 ha. La fréquence de ruissellement pour ce type de parcelle est de $60 \%$ (à raison de $33 \%$ de ruissellement diffus tardif et $27 \%$ de ruissellement diffus précoce), avec un indice de ruissellement de 100 (tableau VII).

Les indices $P$ s et $R \mathrm{t}$, calculés pour les différentes cultures et systèmes d'exploitation (tableau IX), permettent d'évaluer l'effet des fonctionnements d'exploitations sur le risque de ruissellement.

\section{Fonctionnement traditionnel TR}

Pour ce fonctionnement, les proportions de surfaces à risque de ruissellement sont assez élevées sur les céréales d'automne $(P \mathrm{~s}=40 \%)$. Ceci s'explique par la mécanisation de ces exploitations, à base d'outils traînés (tableau I), avec lesquels la préparation des lits de semence se fait en plusieurs passages. Compte tenu de sa facilité de conduite et de sa rentabilité, le maïs occupe plus de $50 \%$ de la surface cultivée, avec des retours fréquents. Dans la mesure où ces exploitations ne cultivent que du maïs grain, les chantiers de récolte présentent des risques de ruissellement quasi nuls. Malgré une forte proportion de céréales d'automne à risques, le risque global de ruissellement de ce fonctionnement est relativement faible (total $R \mathrm{t} / 100=16$ ), du fait de la faible surface cultivée ( 4 ha en moyenne par exploitation, soit $5 \%$ de la surface cultivée de la zone d'étude (tableau I).

\section{Exploitations en début d'intensification DI}

Dans ce cas-ci, les outils de travail du sol sont identiques à ceux des exploitations traditionnelles. Les risques liés aux céréales d'automne sont donc du même ordre de grandeur $(P \mathrm{~s}=50 \%)$. Mais l'accroissement des surfaces de céréales d'automne et l'introduction du maïs fourrager augmentent la charge de travail à l'automne, d'où une forte proportion de chantiers de récoltes nus durant tout l'hiver et une valeur de $P$ s élevée $(P s=80 \%)$. De plus, le maïs fourrager est implanté avec des retours fréquents et cette quasi-monoculture de

Tableau VIII. Principe de calcul des indices de risques de ruissellement pour un fonctionnement d'exploitation donné. Exemple du calcul des risques de ruissellement des céréales d'automne.

\begin{tabular}{|c|c|c|c|c|c|c|c|c|}
\hline Agriculteurs & $\begin{array}{c}\text { Surface des } \\
\text { céréales } \\
\text { d'automne } \\
\text { dans } \\
\text { l'assolement }\end{array}$ & $\begin{array}{l}\text { Rotation } \\
\text { pratiquée }\end{array}$ & $\begin{array}{l}\text { Type de } \\
\text { parcelle }\end{array}$ & $\begin{array}{c}\text { Surface } \\
\text { du type } \\
\text { de parcelle } \\
\\
\text { Si (ha) }\end{array}$ & $\begin{array}{c}\text { Fréquence } \\
\text { du risque } \\
\text { de } \\
\text { ruissellement* } \\
\text { fi }\end{array}$ & $\begin{array}{c}\text { Indice } \\
\text { de risque } \\
\text { de } \\
\text { ruissellement* } \\
\\
R i\end{array}$ & $\begin{array}{c}\text { Proportion } \\
\text { de surface } \\
\text { à risque } \\
\text { pourles } \\
\text { céréales } \\
\text { d'automne } \\
\text { Si*fi }\end{array}$ & $\begin{array}{c}\text { Risque } \\
\text { de } \\
\text { ruissellement } \\
\text { pour les } \\
\text { céréales } \\
\text { d'automne } \\
\text { Si*Ri }\end{array}$ \\
\hline 1 & 4 & B-O & $\begin{array}{c}4 \text { passages } \\
\text { après céréale }\end{array}$ & 4 & 0,66 & 125 & 2,64 & 500 \\
\hline \multirow[t]{2}{*}{2} & 12 & $\mathrm{M}_{5}-\mathrm{B}-\mathrm{B}-\mathrm{O}$ & $\begin{array}{l}2 \text { passages } \\
\text { après maïs }\end{array}$ & 4 & 0,60 & 100 & 2,4 & 400 \\
\hline & & & $\begin{array}{c}2 \text { passages } \\
\text { après céréale }\end{array}$ & 8 & 0 & 0 & 0 & 0 \\
\hline $\begin{array}{l}\text { Total pour le } \\
\text { fonctionnement } \\
\text { ( } m \text { agriculteurs) }\end{array}$ & & & & $\sum_{i}^{n n}\left(S_{i}\right)$ & & & $P_{\mathrm{S}}=\frac{\sum_{T}^{m}(S \mathrm{~S} * f i)}{\sum_{\mathrm{T}}^{m} S \mathrm{i}}$ & $R \mathrm{t}=\sum_{1}^{m}(S \mathrm{i} * R \mathrm{i})$ \\
\hline
\end{tabular}

* Voir tableau VII. 
Tableau IX. Indices $P$ S et $R \mathrm{t}$ des différentes cultures de chaque fonctionnement d'exploitation ( $m$ donne le nombre d'exploitations prises en compte dans le calcul).

\begin{tabular}{|c|c|c|c|c|c|c|c|c|c|c|}
\hline \multirow[t]{2}{*}{$\begin{array}{l}\text { Fonctionnement } \\
\text { d'exploitation }\end{array}$} & \multirow[t]{2}{*}{$\mathrm{m}$} & \multicolumn{2}{|c|}{$\begin{array}{c}\text { Céréales } \\
\text { d'automne }\end{array}$} & \multicolumn{2}{|c|}{$\begin{array}{l}\text { Chantiers } \\
\text { de récolte }\end{array}$} & \multicolumn{2}{|c|}{$\begin{array}{l}\text { Culture } \\
\text { de maïs }\end{array}$} & \multicolumn{2}{|c|}{$\begin{array}{c}\text { Culture de soja, } \\
\text { betterave }\end{array}$} & \multirow{2}{*}{$\begin{array}{c}\text { Total } \\
\mathrm{R} t\end{array}$} \\
\hline & & Ps & $\mathrm{R} t(/ 100)$ & Ps & $\mathrm{R} t(/ / 00)$ & Ps & $\mathrm{R} t(/ 100)$ & $\mathrm{Ps}$ & $\mathrm{R} t(/ 100)$ & \\
\hline TR & 7 & 40 & 10 & 0 & 0 & 50 & 6 & 0 & 0 & 16 \\
\hline DI & 7 & 50 & 38 & 80 & 18 & 80 & 21 & 100 & 2 & 79 \\
\hline INT & 11 & 10 & 10 & 30 & 48 & 50 & 31 & 80 & 27 & 116 \\
\hline DVA & 4 & 10 & 14 & 0 & 0 & 80 & 8 & 100 & 3 & 25 \\
\hline $\mathrm{CO}$ & 2 & 10 & 1 & 0 & 0 & 90 & 6 & 100 & 9 & 16 \\
\hline
\end{tabular}

maïs fourrager engendre un risque très élevé de ruissellement sur cette culture $(P \mathrm{~S}=80 \%)$. Les proportions de surface à risque élevé, associées à une logique d'accroissement des surfaces de culture ( $20 \%$ de la zone d'étude) confèrent à ce fonctionnement un niveau de risque de ruissellement global relativement important (total $R \mathrm{t} / 100=79$ ).

\section{Cas du fonctionnement INT}

Il gère $56 \%$ des surfaces cultivées de la zone d'étude et l'intensification de la production de céréales nécessite l'utilisation d'outils animés, de semis combinés et le recours au binage. $P$ s prend par conséquence les valeurs les plus faibles sur cultures d'automne. Le recours à ces techniques diminue de près de 4 fois la proportion de céréales d'automne à risque par rapport aux systèmes $T R$ et $D I$. La plus grande surface labourable et l'équipement de ces exploitations intensives leur permet une plus grande souplesse dans la répartition du maïs (moindre spécialisation des parcelles) et la réalisation de semis automnaux, ce qui limite les successions de maïs. Ainsi, la proportion de chantiers de récolte nus est faible $(P \mathrm{~s}=30 \%)$. La nonspécialisation du parcellaire abaisse également pendant l'été l'intensité des risques sur culture de maïs $(P \mathrm{~s}=50 \%)$. Certaines exploitations binent aussi les betteraves et le soja, ce qui conduit à un $P$ s légèrement plus faible que pour les autres fonctionnements. Cependant, bien que les proportions de surface ruisselantes des différentes cultures soient modérées, le risque global est le plus élevé (total $R \mathrm{t} / 100=116$ ), en raison de l'importance des surfaces cultivées. Les chantiers de récolte nus contribuent en fait pour moitié à ce risque global.

\section{Fonctionnements diversifiés DVA}

Ce type de fonctionnement où le maïs fourrager disparaît avec l'abandon de l'élevage ne présente pas les risques liés aux chantiers de récolte nus et non repris par un travail du sol. Comme pour les fonctionnements INT, l'équipement s'accompagne de valeurs faibles de $P \mathrm{~S}$ des cultures d'automne. Les forts retours de maïs grain dans les rotations expliquent la valeur élevée de $P \mathrm{~s}$ $(80 \%)$ du maïs. Finalement, l'absence de chantiers de récolte nus, l'équipement et des surfaces cultivées moyennes (17\% de la zone d'étude) mènent pour ce fonctionnement, à un risque global de ruissellement faible (total $R \mathrm{t} / 100=25$ ).

\section{Fonctionnement commercialisateur $C O$}

Quelques exploitations conservent dans ce cas de figure un petit noyau de cultures spécialisées, ne représentant que $2 \%$ de la surface des cultures annuelles du Bas-Chablais. Sur ces surfaces réduites, $P$ s peut prendre des valeurs très fortes en raison de la spécialisation du parcellaire (quasimonoculture de maïs).

Les fonctionnements des exploitations agricoles du Bas-Chablais ont donc des impacts très divers sur les risques de ruissellement. L'intensification des fonctionnements d'exploitation augmente le risque global, non pas par un accroissement des risques par unité de surface cultivée, mais plutôt une extension des surfaces cultivées à risque modéré.

\section{CONCLUSION}

Dans la zone étudiée, le ruissellement affecte deux tiers des parcelles et présente une grande diversité de formes et d'origines. Un premier cas concerne le ruissellement lié à la saturation des bas-fonds où l'hydrodynamique des sols est déterminante. Il existe également un ruissellement « externe », non contrôlé par l'agriculture, provoqué par des débordements des fossés et relevant de problèmes d'aménagement du territoire. Enfin, on observe 
des formes de ruissellement liées à la dégradation structurale superficielle et au tassement des sols. Elles prédominent dans le Bas-Chablais et n'aboutissent pas, compte tenu de l'organisation du parcellaire, à des ruissellements concentrés avec incisions marquées.

Dans le contexte pédologique étudié, les pratiques de travail du sol sont les principaux facteurs de risque de ruissellement. Les situations les plus à risques sont liées à l'implantation des cultures à l'aide d'outils traînés, aux rotations à fort retour de maïs et aux chantiers de récolte laissant le sol nu.

Les fonctionnements d'exploitations traditionnels, ou en début d'intensification, accumulent les pratiques à risque et présentent les plus forts risques de ruissellement par unité de surface labourée. Malgré cela, à l'échelle de la région, le risque global lié au type d'exploitations traditionnelles reste limité, en raison de la faible extension de leurs cultures annuelles. Inversement les systèmes en début d'intensification, avec leur logique d'augmentation des cultures, contribuent notablement au risque global. Les exploitations les plus intensives présentent une situation bien différente :

- des risques par unité de surface modérés, compte tenu d'un équipement et de rotations qui limitent les problèmes de dégradation structurale des sols ;

- un risque global important, en raison de la forte surface des cultures annuelles.

Dans le cas des exploitations traditionnelles, intensives, diversifiées ou commercialisatrices, l'équipement est adapté au besoin de l'exploitation, en relation avec la force tractrice, l'étendue des surfaces cultivée et les impératifs du calendrier cultural. En revanche, pour les exploitations en cours d'intensification, l'équipement et les pratiques de travail du sol ne sont pas remis en cause, alors que la surface cultivée et les contraintes de calendrier s'accroissent.

Tous ces éléments constituent une base pour proposer quelques axes d'action différenciés selon le fonctionnement des exploitations, dans le but de limiter les émissions de contaminants vers les eaux de surface. Pour les exploitations traditionnelles, diversifiées ou commercialisatrices, il semble peu intéressant d'envisager des actions particulières, dans la mesure où le niveau de risque global qu'elles génèrent est faible. Les efforts doivent porter en priorité sur les équipements et pratiques de travail du sol des exploitations en début d'intensification. Il peut s'agir concrètement d'actions de formation (gestion des chantiers de récolte, décompactage), ou, au cas par cas, d'introduction d'outils animés dans l'exploitation, de recours à des structures communes d'utilisation d'outils animés, ou de sous-traitance des travaux de semis à des entrepreneurs. Pour les exploitations intensives, déjà bien équipées, la possibilité de réduire la proportion de surface ruisselante est beaucoup plus restreinte. L'essentiel de l'effort doit porter sur la maîtrise des risques au niveau des chantiers de récolte, avec par exemple, un travail superficiel du sol après récolte. Il semble néanmoins que dans le cas de ces systèmes, la maîtrise des pertes ne passe plus tant par la réduction des émissions, que par leur interception lors du transfert vers le réseau hydrographique. Cette capacité d'interception et de rétention des polluants associés au ruissellement dépend de l'organisation du parcellaire et notamment de la présence des surfaces enherbées, qu'il s'agisse de prairies ou de bandes enherbées (Dillaha et al, 1989 ; Weller et al, 1995). Il convient donc de démontrer l'intérêt et la faisabilité de ces dispositifs tampons.

Cette étude montre qu'il existe, dans la région étudiée, des relations étroites entre logiques de développement agricole, fonctionnement, équipement des exploitations et risques de ruissellement. De telles relations n'existent pas forcément dans d'autres contextes de milieu ou de développement agricole. Mais la démarche adoptée, basée sur une analyse de la diversité milieu-pratiques-systèmes d'exploitation et sur la hiérarchisation des facteurs de risque, peut être reproduite. Elle pourrait être utile en particulier pour la mise au point des indicateurs agri-environnementaux appliqués à des exploitations agricoles (Girardin, 1996) ou des bassins versants.

\section{RÉFÉRENCES}

Auzet AV, Boiffin J, Papy F, Maucorps J, Ouvry JF (1990) An approch to the assessment of erosion forms and erosion risks on agricultural land in the Northen Paris Basin, France. In : Soils Erosion and Agricultural Land, John Wiley, Chichester, 384-400

Beaujean JM, Cros X (1993) Typologie des exploitations des cantons périurbains de seconde couronne. Document interne GIS Alpes du Nord, $46 \mathrm{p}$

Boiffin J (1984) La dégradation structurale des couches superficielles du sol sous l'action des pluies. Thèse docteur ingénieur Ina-PG, $320 \mathrm{p}+$ annexes

Boiffin J, Eimberk M, Papy F (1988) Influence des systèmes de culture sur les risques d'érosion par ruissellement concentré. I. Analyse des conditions de déclenchement de l'érosion. agronomie 8, 663-673 
Bui Huu Tri, Monnier G (1973) Étude quantitative de la granulation des sols sous prairie de graminées. II. Les paramètres de granulation en relation avec la constitution physique du sol et le système racinaire. Ann Agro 6, 651-679

Cipel (1988) Rapport de l'étude des pollutions d'origine diffuse dans le Bassin lémanique. Ouvrage collectif, Cipel Lausanne, $119 \mathrm{p}$

Cristofini B (1985) La petite région vue au travers du tissu de ses exploitations. Un outil pour l'aménagement et le développement rural. In : Études et recherches sur les systèmes agraires et le développement $6,44 \mathrm{p}$

Cristofini B, Roybin D, Étaix F (1994) Caractériser le développement régional, est-ce parler de sa qualité ? Une typologie des 128 cantons des Alpes du Nord. In : Études et recherches sur les systèmes agraires et le développement, 28, 293-318

Cros X (1994) Influence du développement des activités humaines sur les risques de transfert de pollution, phosphatée au lac Léman. Étude sur 20 communes du Genevois haut-savoyard. Mémoire de DESS, université de Poitiers, $30 \mathrm{p}$

Dillaha TA, Reneau RB, Mostaghimi S, Lee D (1989) Vegetative filter strips for agricultural non point source pollution control. Am Soc Agric Eng 2, 513519

Dupont S (1994) Typologie et cartographie des sols du Bas-Chablais. Mémoire de MST, université SavoieChambéry, $34 \mathrm{p}$

Girardin P (1996) Les indicateurs : un outil pour les agronomes ? Document interne Inra Colmar, $14 \mathrm{p}$

Le Bissonnais Y (1988) Analyse des mécanismes de dégradation et de la mobilisation des particules de terre sous l'action des pluies. Thèse de doctorat, université d'Orléans, $176 \mathrm{p}$

Le Bissonnais Y (1990) Experimental study of soil surface crusting processes. Catena 17, 13-18

Lelong F, Roose E, Darthout R, Trévisan D (1993) Susceptibilité au ruissellement et à l'érosion en nappe de divers types texturaux de sols cultivés ou non cultivés du territoire français. Expérimentations sous pluies simulées. Sci Sol 31(4), 251-279

Ludwig B (1992) Érosion par ruissellement concentré des terres cultivées du nord du Bassin parisien : analyse de la variabilité des symptômes d'érosion à l'échelle du bassin versant élémentaire. Thèse de doctorat, université Strasbourg-I, $201 \mathrm{p}$
Marty JR, Fioramonti S (1970) Comparaison de diverses rotations sur sols limoneux mal structurés, effet améliorant des cultures fourragères. Ann Agro 3, 269-286

Merot P (1991) Inventaire des processus de transfert dans un bassin versant. Rôle de l'organisation des sols. In : Séminaire du département Sciences du sol, Dijon, Inra, 1-16

Monnier G, Stengel P (1982) La composition granulométrique de sols : un moyen de prévoir leur fertilité. Bull Tech Inf (FRA 370.372), 503-512

Monnier G, Boiffin J, Papy F (1986) Réflexions sur l'érosion hydrique en conditions climatiques et topographiques modérées. Cas des systèmes de grande culture de l'Europe de l'Ouest. Cah Orstom, sér Péd $2,123-131$

Mosimann T, Maillard A, Musy A, Neyroud JA, Rüttimann M, Weisskopf P (1991) Lutte contre l'érosion des sols cultivés. Liebefeld, Berne, $187 \mathrm{p}$

Novotny D (1994) Non point pollution. Wat Qual Int 1, 24-31

Papy F, Boiffin J (1988) Influence des systèmes de culture sur les risques d'érosion par ruissellement concentré. II. Évasion des possibilités de maîtrise du phénomène dans les exploitations agricoles. agronomie $9,745-756$

Papy F, Douyer C (1991) Influence des états de surface du territoire agricole sur le déclenchement des inondations catastrophiques. agronomie 11, 201-215

Rieffel P (1975) Étude des sols de la région de Thonon, Haute-Savoie. Mémoire de DEA, université de Paris-VI, $39 \mathrm{p}$

Roybin D (1991) Typologie fonctionnelle des exploitations et évolution de la production de reblochon fermier en Haute-Savoie. Ethnozootechnie 47, 3-17

Trévisan D, Lelong F (1992) Influence de la dégradation structurale superficielle sur le ruissellement enregistré sous pluies simulées. Sci Sol 4, 248-261

Valentin C (1981) Organisations pelliculaires superficielles de quelques sols de régions subdésertiques. Thèse de l'université Paris-VII, $213 \mathrm{p}+$ annexes

Weller CM, Watzin MC, Wang D (1995) The role of wetland in reducing phosphorus loadings to surface water in eight watersheds in the lake Champlain basin. University of Vermont, Burlington, $22 \mathrm{p}$ 